\title{
Agent-based model for simulating households' self-evacuation decision in high-rise buildings under critical infrastructure failures induced by a slow- onset flood conditions - A case study in Paris
}

\author{
Abla M. Edjossan-Sossou ${ }^{12}$, Marc Vuillet ${ }^{1}$, Rasool Mehdizadeh ${ }^{2}$ and Olivier Deck ${ }^{2}$
}

Received: 29/03/2020 / Accepted: 12/10/2020 / Published online: 30/11/2020

\begin{abstract}
Generating well-informed and reliable predictions for disaster evacuation is a large challenge. Crisis and disaster management policymakers have to deal with poor data quality, a limited understanding of households' behaviour dynamics, and uncertainty regarding the effects of the various actions/measures in place. Agent-based simulation models are frequently used to support decisions when planning disaster evacuation procedures. However, one of the most important aspects of this issue, which is social influence, is not often considered. Most of existing evacuation models largely overlook the importance of the households' behaviours and social influences, which leads to oversimplified models. Moreover, it is almost impossible to find models in the literature that focus on the extrinsic decision-making factors of some evacuees, such as compromised lifelines, in the case of catastrophic events. In contrast to the existing evacuation models, this paper suggests a probabilistic agent-based model that relies on the loss of different lifelines as factors affecting evacuees' decision-making in addition to some intrinsic factors that are used to characterise the propensity of households to evacuate and explicitly allow for social contagion as well as uncertainties to be considered. This model, in which all the variables are considered uncertain and Monte Carlo Simulations are run to estimate the confidence range of the predictions, is tailored to estimate the potential number of inhabitants that have not been evacuated in high-rise buildings in the face of critical infrastructure failures induced by a slow-onset flood and/or the actions taken during the related crisis, considering different uncertainties that may affect the reliability of the prediction. The model has been specifically designed to predict the dynamics of households' self-evacuations in fourteen residential high-rise buildings located in a flood-prone area in Paris. This paper
\end{abstract}

\footnotetext{
${ }^{1}$ Université Gustave Eiffel, Lab'Urba EA3482, Ecole des Ingénieurs de la Ville de Paris(EIVP), Paris, France

${ }^{2}$ Université de Lorraine, CNRS, CREGU, GeoRessources, UMR 7359, Ecole des Mines de Nancy, Nancy, France

*Corresponding author : Email : medjossan@gmail.com
} 
describes the suggested model and also reports the results of an illustrative case study in which three scenarios are simulated to demonstrate the applicability of the model, to test its effectiveness and to explore the uncertainty regarding some modelling assumptions using sensitivity analysis.

Key words: Agent-based modelling, uncertainty, evacuation, social influence, flood, high-rise buildings

\section{INTRODUCTION AND BACKGROUND}

In light of the recent natural disasters throughout the world, governments and academics are gradually becoming aware of the vulnerability of the territories affected by these disasters. This awareness is even more important when the vulnerability could be increased by the cascading effects resulting from the level to which critical infrastructures are interconnected. Cities have started to anticipate the potential damage of major events and to identify appropriate management strategies to effectively cope with these disasters in the future to achieve their resilience objectives, including the safety and the well-being of the population.

From this perspective, ensuring the resilience of Paris and the Ile-de-France region against a major flood of the Seine river is one of the crucial challenges of the public authorities and risk management decision-makers. According to the OECD (2014a), "a major Seine flood would today have important potential impacts on well- being, and on the activities of the government and businesses". Indeed, experts estimate that a flood of the Seine river and its tributaries of the magnitude of the historic event of 1910 will cost at least thirty billion euros and affect up to 5 million residents (OECD, 2014b). During this historic flooding, the water level exceeded $8 \mathrm{~m}$ at the Paris-Austerlitz measuring station and rose over a period of 10 days, with receding occurring over a period of more than a month. Currently, a flood of this magnitude is estimated to be a 100 -year flood.

Such an event would lead to long lasting damage and cause severe impairment to technical networks (electricity, sewage, transportation, urban heating and cooling systems, etc.). For instance, the power distribution would be significantly disturbed, as more than 377,000 domestic and business customers in Paris would experience power cuts, while an important part of road network could be blocked, making it impossible to travel from one bank to the other. There would also be thousands of residents who would undeniably seek evacuation. To date, at least 290,000 people are living within the potential evacuation zone reported in the Seine Basin (Fujiki, 2017). The serious flooding events in May-June 2016 and JanuaryFebruary 2018 that impacted the Seine Basin, during which some people were evacuated from their homes while others stayed in their homes without electricity (Longjumeau, Gournay, etc.), are reminders of the degree of vulnerability of the Ile-de-France Region. Consequently, it seems advisable to seriously consider that a mass evacuation may occur in the case of a major 
flood of the Seine, which would lead to a chronic reduction in the well-being of the people involved.

Therefore, public authorities and decision-makers started questioning their ability and preparedness to cope with a probable evacuation of people living within the potential evacuation zone, including the number of people to care for, shelter availability and locations, evacuation routes, etc. (Fujiki \& Laleau, 2019). Designing appropriate evacuation plans is a crucial aspect of disaster preparedness. It is an extremely challenging task that implies responses to the following questions: who, when, where and how to evacuate? These responses will provide the information required to better plan the operational implementation of an evacuation. Thus, one of the most important steps of a potential evacuation plan in Paris is the estimation of the number of residents who must be evacuated over time to provide estimates for designing strategies to respond to the appropriate number and location of these residents.

We present herein an agent-based model for estimating people's decisions to evacuate by their own means. This study attempts to provide a tool for understanding the following question: "how many residents would decide to stay home under slow-onset major flooding that is not life-threatening to the residents but is lifeline-compromising?". The model was developed to help risk managers in the dynamic prediction of households' self-evacuation decisions in the face of the reduction of their well-being following a slow-onset flood involving cascading disruptions of critical infrastructures. This work was conducted under the RGC4 project $^{3}$, which aimed to develop operational tools to cope with technical network failures at the grand Paris scale to improve the resilience of the Paris urban area against extreme floods. While the main objective of this work is the estimation of people remaining inside their dwellings at a given time during a flooding disaster, it also aims to address three research questions.

First, it considers the effect of social contagion among neighbours, relying on the assumption that social contagion will contribute to spreading the decisions of the households that chose to leave their dwellings among their neighbours and, thus, lead to more households to evacuate (Riad et al., 1999; Kakimoto \& Yamada, 2014; Bangate et al., 2017). Second, it assumes that, in the case of a chronic disaster leading to the reduction of the households' welfare, their decision to evacuate or not could be influenced by their living conditions. To the best of our knowledge, most of the existing studies modelled the evacuation decision considering mainly (recommended or mandatory) evacuation orders issued by authorities and/or signs presaging the imminent onset of the hazards as decision-making triggering event(s). The existing research has not addressed modelling evacuation with regard to the reduction of the households' wellbeing due to the loss of lifelines provided by the technical networks as a triggering factor of their decisions to evacuate (Tobin et al., 2011). Thus, the model is developed considering the failures of technical networks as evacuation decision triggering events. It is assumed that these events could occur solely or simultaneously with others due to cascading effects or not. It, therefore, investigates the appropriate approach to combine their effects on the households' decisions to obtain more robust outcomes. Finally, it implicitly accounts for the uncertainty

\footnotetext{
${ }^{3}$ https://anr.fr/Project-ANR-15-CE39-0015
} 
associated with the input data and the simulation running outputs, while most of the other evacuation models do not necessarily integrate uncertainty into their reasoning (Ronchi et al., 2013; Tavares \& Ronchi, 2015).

The proposed model is a probabilistic model so that various uncertainties about the quality of data, the heterogeneity of households, the evolution of the households' environment (occurrence time of the evacuation triggering events), etc. can be considered. The proposed model allows the running of Monte Carlo simulations to improve its performance through sensitivity analysis and also deals with a slow-onset hazard, which is contrary to most studies on the evacuation of people, which mainly focus on fast kinetics hazards, such as hurricanes, fire, industrial or nuclear accidents, etc. The target site of this evacuation model is the batch of residential high-rise buildings located along the Seine within the 15th district in Paris, mainly because they are the most densely populated residential buildings within the flood prone area within the Seine basin. It is assumed that the target residents have the same characteristics as most of the residents of the Ile-de-France Region (Fujiki, 2017), i.e., three persons in four are motorised and approximately $90 \%$ could ensure their self-hosting (secondary residence, hosted by parents/friends/relatives, hotels, etc.). Some of these characteristics are used in the model as intrinsic evacuation decision-making factors to estimate the residents' propensity to evacuate by their own means.

Although this model investigates the evacuation decision-making process of households living in high-rise buildings, it will not focus on the choice of escape route, the evacuation speed, the escape behaviour (collaborative vs. competitive) or the evacuation completion time, as in the few studies targeting high-rise buildings, but will account for the social influence among residents, as well as the combination of the effects of more than one evacuation triggering event. The uniqueness of the suggested model lies in the emphasis on social contagion of evacuation decision-making among neighbours, the linking of evacuationdecision making to the loss of one or more lifelines as evacuation decision-making factors besides some evacuees' intrinsic characteristics, which are commonly used in evacuation modelling, and the explicit consideration of uncertainty through a probabilistic approach.

The remainder of this paper is structured as follows. Section 2 is devoted to a state of the art household evacuation decision modelling using agent-based modelling. Section 3 describes the model developed towards obtaining the goal of this study. Section 4 presents and discuss the results of a demonstrative example to examine the applicability and the effectiveness of the proposed model. Finally, conclusions are drawn in section 5.

\section{STATE OF THE ART ON AGENT-ORIENTED EVACUATION MODELLING}

Due to the variety of hazards, factors influencing evacuation (decision or completion), modelling approaches and evacuation aspects investigated (information dissemination and warning, logistical concerns, mode choice, route and destination selection, timing, total demand, traffic assignment, zoning, etc.), a significant amount of work is done on evacuation 
modelling. This section provides an overview of the determinants of households' evacuation decisions and the use of agent-based modelling in the households' evacuation decision.

\subsection{Factors influencing a household's decision to evacuate in the face of a natural disaster}

Studies on whether to participate in an evacuation are mainly carried out from the individuals' or households' point of view. Generally, empirical studies or logistic regression models constructed on the basis of survey data are used to determine the factors influencing evacuation decision-making. A review of the evacuation literature shows that several factors could lead households to decide whether to evacuate an area threatened by a hazard (Dash \& Gladwin, 2007; Ahsan et al., 2016). They could be of an intrinsic nature and an extrinsic nature. In short, the ability or propensity depending mostly on their intrinsic factors (Rabemalanto et al., 2020) and the willingness of households to evacuate are the main characteristics that can facilitate or hinder their evacuation decisions. Because the significance of the influence of these factors on the households' decisions could vary depending on the context (Murray-Tuite \& Wolshon, 2013), identifying households likely to evacuate can prove complex (Wright \& Johnston, 2010).

The intrinsic factors involve the households' socio-demographic characteristics, such as the household size (Luathep et al., 2013), the presence of vulnerable people, such as children, senior citizens or persons with disabilities (Lim et al., 2016), the ownership of and access to a vehicle (Wright \& Johnston, 2010), the access to an available relocation place (Chang et al., 2009), the presence of pets (Solis et al., 2010), etc. The socio-demographic information contributes to the modelling of the behavioural features of the households at a particular location at a given time. Although the propensity to evacuate is not sufficient to predict the households' evacuation decisions successfully, it is a key parameter in the modelling of their willingness or reluctance to self-evacuate. The lower the propensity, the higher the need to be cared for by public authorities or emergency services during an evacuation. Apart from sociodemographic characteristics, the intrinsic factors may include people's risk perception (Jumadi et al., 2018).

Researchers also identified the following extrinsic factors related to households' evacuation decision-making processes: communication/information concerning the risk (Wright \& Johnston, 2010), influence of the society in which the households live, such as following the example of their neighbours after observing them evacuate (Lindell et al., 2005; Nagarajan et al., 2012), environmental cues, such as sights, smells or sounds, indicating the onset of the hazard (Lindell et al., 2015), liveability or not of their dwellings and neighbourhood resulting from disruptions of lifelines provided by technical networks (Chatterjee \& Mozumder, 2015), etc. Although some attention is being given to the loss of lifelines as a determinant for disaster evacuation (Kailes \& Enders, 2007), only a few works tried to identify the influence of the various technical networks on the households' decision in the face of disasters. It has been found that power supply is one of the most vital technical networks, the failure of which can 
greatly affect the well-being of households (Schultz et al., 2003; Reed et al., 2010; Nateghi et al., 2011; Chatterjee \& Mozumder, 2015).

Although previous studies prove that the households' evacuation decisions depend not only on their own characteristics or on the features of the hazard but also upon their external environment, generally, most evacuation cases are modelled considering that the evacuation process is triggered mainly by the onset of a hazard and/or the issuance of evacuation orders (Han et al., 2007; Fang et al., 2011; Madireddy et al., 2011; Zale \& Kar, 2012; Song \& Yan, 2016). By doing so, the models ignore the possibility that the households' decisions may be influenced by their external environment. The developed model aims to address this gap by integrating technical failures as potential triggering events of the evacuation decision process.

\subsection{Agent-based modelling in disaster evacuation engineering}

A plethora of studies exist on disaster evacuation modelling thanks to the increasing level of realism provided by simulations. Agent-based modelling (hereafter ABM) is one of the most used approaches to this end (like in the studies of Chen \& Zhan, 2008; Christensen \& Sasaki, 2008; Hawe et al., 2012; Mostafizi et al., 2017; Ukkusuri et al., 2017; Kasereka et al., 2018; Olsvik et al., 2018; etc.). Agent-oriented models allow the behaviours of heterogeneous individual components of a complex system, which function autonomously to achieve their specific desired objectives in a common environment through mutual environmental interactions, to be described (Albino et al., 2007). Each individual component or agent has its own characteristics, states and objectives. The agents are also able to make their own decisions and update their state while relying on defined rules. According to Nikolic \& Kasmire (2013), $\mathrm{ABM}$ enables the possible complex and non-linear variations in the state of a system, across time and space to be investigated to derive and understand the plausible futures, trends, tendencies or behaviours that can occur under specific circumstances. One of the main strengths of ABM is its flexibility; the agents' attributes/goals/behaviours and modelling assumptions are easily changed to test several cases. Rangel-Ramirez et al. (2019) stated that although agent-based models "do not capture all aspects of human and social behaviour in risk situations such as grouping, social cohesion, decision-making under stress, aiding and collaborative behaviour, etc.; this is the presently most adequate modelling scheme for the representation of human behaviour during evacuation scenarios". ABM is, thus, particularly well-suited for this work due to the difficulty of determining the choice of a random population of households to stay or to leave when they receive evacuation orders and/or when their living conditions are worsened by the a slow-kinetics flood associated with technical network failures.

However, it is worth noting that $\mathrm{ABM}$ is a random approach by nature. Thus, the studies based on ABM could be inherently limited by the quality of the data. Generally, the existing agent-oriented models address the different aspects of evacuation modelling deterministically and do not necessarily account for the natural variations in the modelled agents' population, while the evacuee behaviours are commonly judged as the largest uncertainties (Wang et al., 2020). Indeed, most often, apart from the localisation of the agents, agent-based models 
consider homogenous characteristics (Rangel-Ramirez et al., 2019), which makes it difficult to properly calibrate the models, to incorporate observational data into the models (thus, they lack the diversity that exists in the real world) and to quantify the uncertainty in the outputs. In fact, evacuation plans or strategies can be effective only to the extent that managers actually use the available information to make their decisions. In places where the households' characteristics are heterogeneous, the households' decisions might vary considerably.

To the best of our knowledge, only a few evacuation modelling studies attempt to fill this gap by accounting for uncertainty in various ways. For instance, Fraser et al. (2014), who suggested a method incorporating, among other parameters, an uncertain evacuation departure time into an existing anisotropic least-cost path distance framework, handled the uncertainty in the evacuation time by running 500 simulations of evacuation times for each scenario and for each individual agent in the population to generate an average evacuation time. Liu et al. (2012), Lv et al. (2013), and Rangel-Ramirez et al. (2019) adopt probabilistic approaches to deal with uncertainty. In line with these few studies which account for uncertainty in the evacuation modelling, this work proposes a probabilistic model intended to systematically address the uncertainty in the input data and to provide possible values for the evacuation demand in various scenarios.

\section{PRESENTATION OF THE DEVELOPED MODEL}

This section provides a description of the developed prototype model that can be used as a potential training or decision-support tool by the Parisian crisis management services. The model is implemented in Mathematica and allows geographical coordinates to be imported to delineate the simulation environment through a $2 \mathrm{D}$ representation of each building within this environment. The model encompasses two major modules that are not editable by the user: study area and hazard modules. However, one could adapt the model to his own specific needs by introducing information describing the desired simulation outline and/or hazard. As a probabilistic model, it relies on a random sampling of almost all the variables by drawing from defined distributions (mainly uniform and normal shapes), except for the calculation timestep. Any instantiation and any simulation are thus unique and may give results differing from each other. Moreover, it is designed to run a single simulation, as well as Monte Carlo simulations while keeping in mind that a large number of a single simulation outcomes need to be studied to obtain a more realistic view of the households' behaviours and improve the confidence in the obtained results through statistically meaningful insights.

\subsection{Presentation of the target site}

Although the model is expected to be applicable to any evacuation situation due to the studied hazardous conditions, this first version has been developed for a specific area in Paris. The target area, representing the environment module of the model, corresponds to the 15th district in Paris. This flood-prone area situated on the Seine waterfront (Figure 1a) is 
characterised by a spatial concentration of approximately twenty high-rise buildings, of which 14 are of private residential use, making this the most densely populated area in Paris (INSEE, 2016). It is worth noting that the model is intended to study the evacuation of the households facing chronic disaster impacts resulting from slow-kinetics flooding. Thus, only the 14 residential buildings classified into two categories (11 co-ownership buildings and 3 social housing buildings) are selected. These towers of 20 to 30 storeys (Figure 1b) consist of a total of 3,175 apartments and house approximatively 10,000 residents.

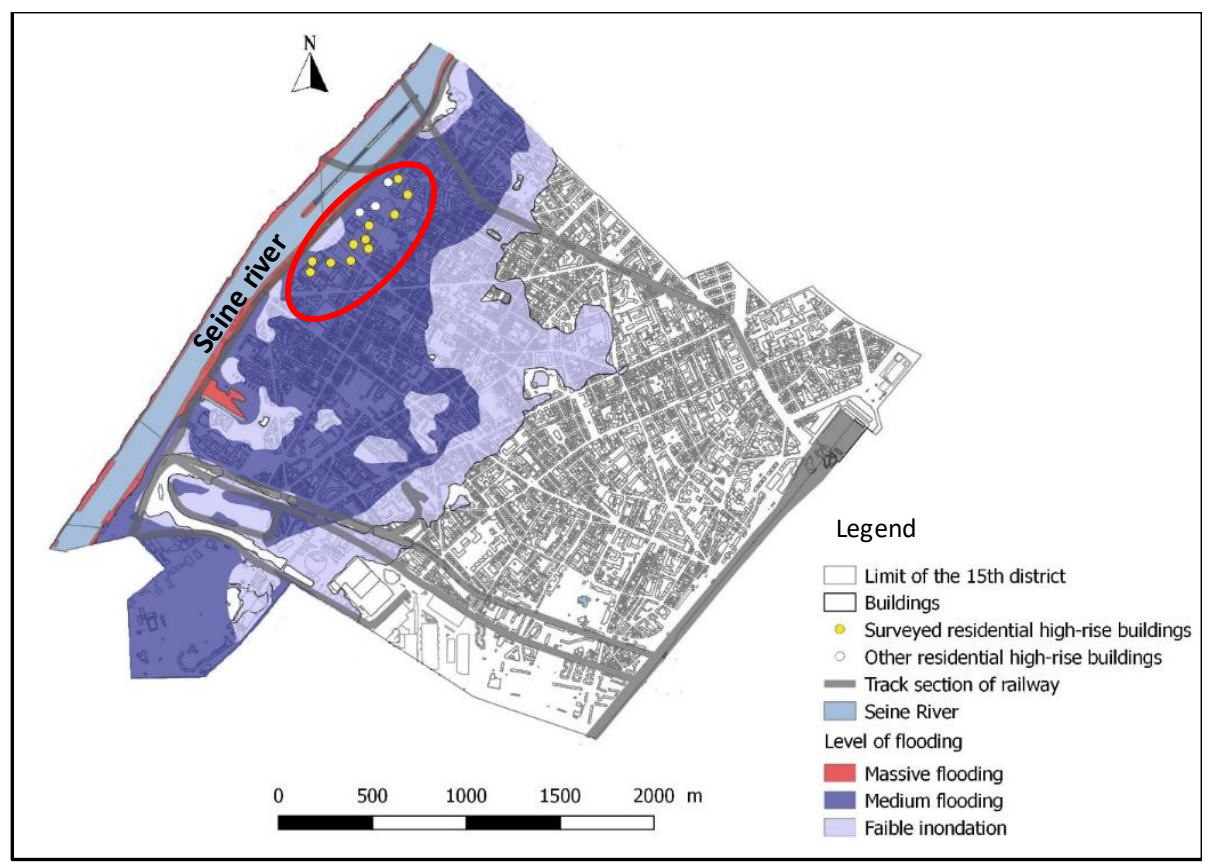

(a)

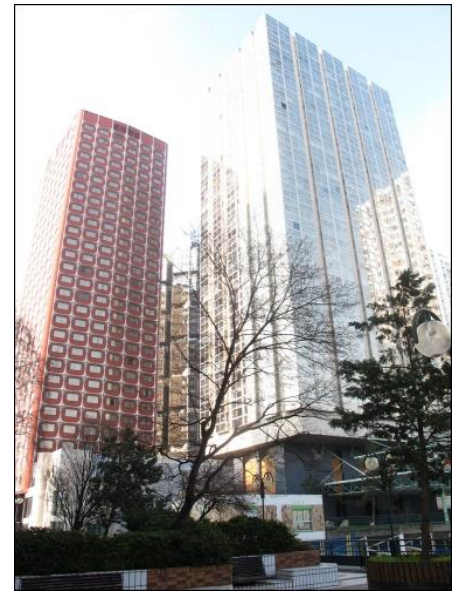

(b)

Figure 1. Outline of the evacuation model:

(a) Flood risk zoning in the 15th district of Paris; (b) High-rise buildings 
In these buildings, all the inhabited apartments are above the 4th floor. Consequently, they are above the highest water level predicted for a major flood of the Seine and the flood water will not enter them. Furthermore, there will not necessarily be any drownings, injuries, or fatalities due to the direct impact of the flood. However, because the towers have four levels of parking lots, two of which are located on two underground floors (with a height of approximately 3 meters each, they are at -6 and -3 meters in relation to street level), water could penetrate underground car parks, mainly by dynamic capillary rise in the foundation walls. These towers are, therefore, vulnerable even before the Seine overflows its banks due to rising water in the basement. The car parks must, therefore, be evacuated even before the residents. Moreover, the residents could face a decline of their well-being resulting from disrupted services and/or reduction in the liveability of their neighbourhood and/or dwelling. Specifically, power outages may lead to elevator shutdowns when alternate power supply devices are not available. When this situation occurs, these towers must be mandatorily evacuated; for safety purposes, the height of the buildings makes it impossible to keep people inside.

\subsection{The hazard module}

A key component of the model is the hazard because the different evacuation triggering events are broken down in a chronological order with regard to the water level at the Austerlitz bridge measuring station. For this purpose, a theoretical hydrograph, which mimics as much as possible one of the historic flooding experienced in 1910, was generated. Their similarity relies mainly on how quickly the maximum crest at the Austerlitz bridge $(8.62 \mathrm{~m})$ is reached and on their duration, which was approximatively two months of the water level being above the flood warning level (which equals to $3.4 \mathrm{~m}$ ) with a height of approximately $6 \mathrm{~m}$. The hazard module consists of a numerical approximation of the theoretical hydrograph generated. This function allows the time or the height to be automatically estimated when the height or the time is provided, respectively. This function is the basis for the activation of the events on which evacuation decisions could be based when their trigger level is reached. To account for uncertainty, the envelope brackets provided at each point of the hydrograph indicate the lowest and the highest possible water levels.

\subsection{Description of the agents}

The main objective is to predict the number of people remaining in their dwelling (i.e., those who will not decide to autonomously evacuate) in the face of a slow-onset major flooding of the Seine river. Thus, the agents are households not individuals, and all actions operate only on households; the assumption is that when a household decides to evacuate, all the members will actually evacuate. Table 1 summarises the agent based-simulation features. 
Table 1. Agent-based simulation features

\begin{tabular}{|c|c|}
\hline Feature & Description \\
\hline Agents & Households \\
\hline Agent attributes & $\begin{array}{l}\text { Discriminating characteristics providing all the insightful } \\
\text { information that relates to the households for their decision } \\
\text { making. They are used to describe each household. }\end{array}$ \\
\hline \multirow{3}{*}{$\begin{array}{l}\text { Agent } \\
\text { behaviours }\end{array}$} & $\begin{array}{l}\text { Evacuation decision-making: the households are able to make a } \\
\text { dichotomous decision (stay at their home or evacuate to a safer } \\
\text { place). }\end{array}$ \\
\hline & $\begin{array}{l}\text { For each calculation, the households follow a simple } \\
\text { probabilistic binary rule by checking if an evacuation triggering } \\
\text { event has occurred or is currently occurring and by observing the } \\
\text { current state of their neighbours' dwellings (either } 0 \text { for } \\
\text { evacuated/non-occupied or } 1 \text { for non-evacuated/ occupied). }\end{array}$ \\
\hline & $\begin{array}{l}\text { When they decide to evacuate, the state of their apartment is then } \\
\text { updated to } 0 .\end{array}$ \\
\hline $\begin{array}{l}\text { Interaction } \\
\text { among agents }\end{array}$ & $\begin{array}{l}\text { It relies on the social influence between households. The } \\
\text { interaction rule is that the probability for a household to evacuate } \\
\text { is increased by a defined factor when a given rate of its } \\
\text { neighbours that decided to evacuate is attained. }\end{array}$ \\
\hline \multirow{2}{*}{$\begin{array}{l}\text { Observed } \\
\text { phenomenon }\end{array}$} & $\begin{array}{l}\text { The model seeks to capture the complex essence of real-world } \\
\text { households' evacuation decision-making processes and the } \\
\text { influential interactions among households. }\end{array}$ \\
\hline & $\begin{array}{l}\text { It will allow the impact of technical network failures and the } \\
\text { social influence on the evacuation decision making processes } \\
\text { within the population located in the flood prone area to be } \\
\text { observed. }\end{array}$ \\
\hline
\end{tabular}

The households are heterogeneous and are characterised by the following:

- an ID number;

- the building and the floor where their dwelling is located (this contributes to estimating the number of their neighbours for each household influence network);

- their size (the number of persons belonging to households not evacuated will be summed up for estimating the remaining people);

- their typology regarding their propensity to evacuate autonomously. On the basis of five household intrinsic factors, which are judged to positively influence the evacuation decision according to previous studies (mainly Fujiki, 2017), the households were 
categorised into three types. These criteria include (1) having a high social index, (2) being able to self-host outside the hazard prone area, (3) owning a motorised transport, (4) having the capacity/potential to self-evacuate and (5) being aware of the risk (consciousness of the real threat on their living area). Using on real socio-demographic data of Paris, a fraction of each type in the whole studied population is calculated and integrated into the model. The three types of households are termed as follows:

○ The "totally autonomous" category are those households who fulfil all five criteria. It is assumed that the higher the propensity to evacuate if needed and the higher the level of propensity to evacuate, the more likely that the household will decide to evacuate.

○ The "highly dependent" category are those households who do not fulfil most of the five criteria. The greater the level of dependence, the lower the propensity to evacuate if needed and the less likely the households will be to decide to evacuate.

- The "moderately dependent" category are those households who do not fulfil a few of the five criteria. This type of household is less likely to decide to self-evacuate than those belonging to the first category, while being more likely than the highly dependent households to evacuate.

- the state of their dwelling, which can be occupied or non-occupied.

The social influence among households is examined, relying on the assertion that "while a simulation can never capture the complexity of a real event, the effect of social influence in an evacuation could be measured by manipulating the proportion of neighbours nearby that have decided to evacuate their homes" (Lamb et al., 2012). For this purpose, it is assumed that a household can have three types of social influence interactions with its neighbours. Their interaction relationship could be horizontal, i.e., when the interacting agents are located on the same floor, vertical, i.e., when they live in the same building, and slanted, i.e., when they live in different buildings (Figure 2). At this stage, the model considers only the horizontal and vertical ones.

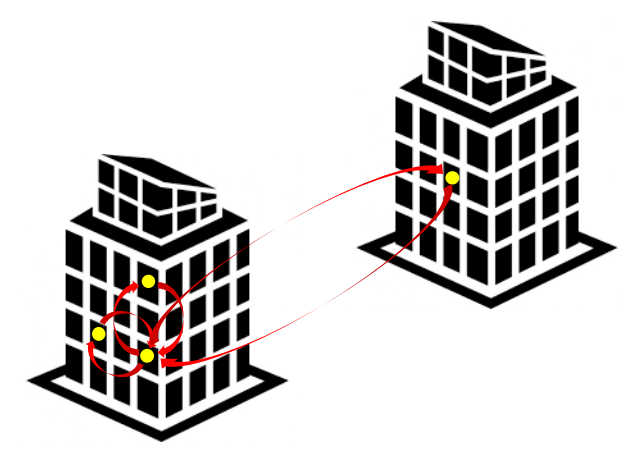

Figure 2. Social influence between households in high-rise buildings 


\subsection{Definition of the evacuation decision triggering events}

The evacuation decision-making process does not occur prior to the flooding and begins only after a triggering event. The latter is meant as any situation that creates the conditions or involves the factors able to influence evacuation decision-making; this in turn, initiates the residents' willingness to evacuate. In evacuation modelling, when an evacuation trigger is known by the households, a temporal distribution of the departure times for those that are responsive to this specific trigger is estimated to construct a departure or response curve, which is also called a mobilisation curve. A response curve represents the proportion of the total evacuation demand over time, and it consists of the cumulative percentage of evacuees' departures over the duration of the evacuation initiated by a given trigger and is used in evacuation modelling to predict when evacuees will evacuate, should this trigger occur. In the real-world, when residents decide to evacuate, they take time to prepare themselves to leave; then, they evacuate if their departure is not hindered by any circumstance or obstacles. However, in this study, it is assumed that their evacuation is effective as soon as they decide to evacuate.

It is reported in the literature that response curves are commonly assumed to have a sigmoid or "S" shape (Fu \& Wilmot, 2004). This shape is because evacuations start slowly, then increase rapidly and finally decelerate and gradually become close to nil when the maximum ratio of people who choose to evacuate tends to be reached. Evacuation decisions over time could follow several distributions, including uniform, sigmoid, Poisson, Rayleigh and Weibull distributions (Cova \& Johnson, 2002; Kalafatas \& Peeta; 2009). As stated by Song \& Yan (2016), these curves are mainly established empirically by relying on the analysis of the households' evacuation behaviours during past disasters or emergency events. They could also be derived from prospective surveys on the households' intended evacuation behaviours in the face of future disasters (Fraser et al., 2013). Some drawbacks to response curves exist, among which is the difficulty of predicting them accurately, the insensitivity of such curves to any changes in the modelling conditions, which may influence the dynamics of households' evacuation decision-making processes, the questionability of the transferability of a given response curve to another evacuation event or a study area different from the one where this curve was established, etc.

In this model, each triggering event is defined by the following:

- The time of its occurrence or the water level at which it could occur. The same trigger could not be characterised simultaneously by both features; the two features could not be simultaneously set for an event because they are linked by the numerical approximation function used to design the hazard module of the model. When a triggering event occurs at a given time and at a specific height, two separate triggers have to be considered, relying either on the occurrence time or on the height. Additionally, if the same type of event occurs several times during the flooding, there must be as many characteristics definitions as there are occurrences.

- The list of the buildings potentially impacted by its effects. 
- The response curves associated with of each of the three typologies of households. Bearing in mind that the less vulnerable people (most autonomous in the case of this study) need less time to evacuate than others (Hofflinger et al., 2019), it is assumed that the main response curve (provided by the literature or obtained from an empirical survey) will be considered as the one of "totally autonomous" households. The others are, thus, obtained by (1) multiplying the evacuation demand of the "totally autonomous" households by a reduction coefficient, as well as (2) shifting the origin of this main curve to the positive direction of the time depending on the difference among the time at which each household type starts to evacuate.

Most of the existing studies modelled the evacuation decision with regard to the issuance of (mandatory or recommended) evacuation orders/instructions (issued by authorities, emergency services or any other means), the distance of the evacuees' locations from the hazard threat or the signs predicting the imminent onset of the latter as evacuation triggering events. However, it has been proven that these factors could induce evacuation decision-making. Therefore, the model is constructed with a series of pre-listed events likely to occur when the water level at Austerlitz reaches some known heights and is liable to lead households to evacuate. They may be activated by the user by defining their specific characteristics. These triggers are as follows:

- Recommended order of the evacuation of people.

- Mandatory order of the evacuation of people.

- Mandatory order of the evacuation of cars (parked in the towers' underground parking).

- Energy supply failure.

- Urban heating failure.

- Food supply disruption.

- Neighbourhood insalubrity.

- Sewage disposal disruption.

- Dysfunction of the components of the transport system (traffic congestion, closed roads, public transport unavailability, etc.).

It could be noted that the above list does not include an important evacuation trigger when facing flooding, which is having water in the dwelling, possibly due to the specificity of the study area (as mentioned earlier; see $\S 3.1$ ). In addition, one can add more triggering events if needed.

Two main scientific challenges were identified while creating the triggers module. The first challenge is the non-availability of the appropriate response curves needed for achieving a good level of realism. Indeed, the response curves to be used for each case study must ideally be generated in the target area. However, currently, there are no data which describe how Parisians living in the studied high-rise buildings (or even how people in Ile-de-France region) evacuate (or will evacuate) after the selected triggers are released. Furthermore, the existing curves 
found in the literature are mainly related to evacuation orders and fast kinetics phenomena (mostly hurricanes). This challenge is addressed by defining fictitious curves because, at this stage, the main aim is to ensure that the model correctly simulates the households' behaviours that are expected to occur during an evacuation resulting from the conditions studied herein.

The second challenge is about how to adequately combine the probabilities of evacuation decision-making deducted from the response curves of several triggers occurring simultaneously. It is assumed that when the situation faced by households becomes worse due to a new event, they could change their mind if they have not evacuated already because the previous triggers did not sufficiently lead them to express their willingness to leave the area. Song \& Yan (2016) conducted an empirical study to question the response curve obtained when two evacuation orders are issued during a disastrous situation (Figure 3). They found that when a second evacuation order is issued 60 hours after the first one, the obtained total evacuation demand rises more quickly than the evacuation demand uniquely associated with the first order; the greater the number of evacuation triggers occurring simultaneously, the higher the total evacuation demand, which justifies the need to combine the effects of triggers.

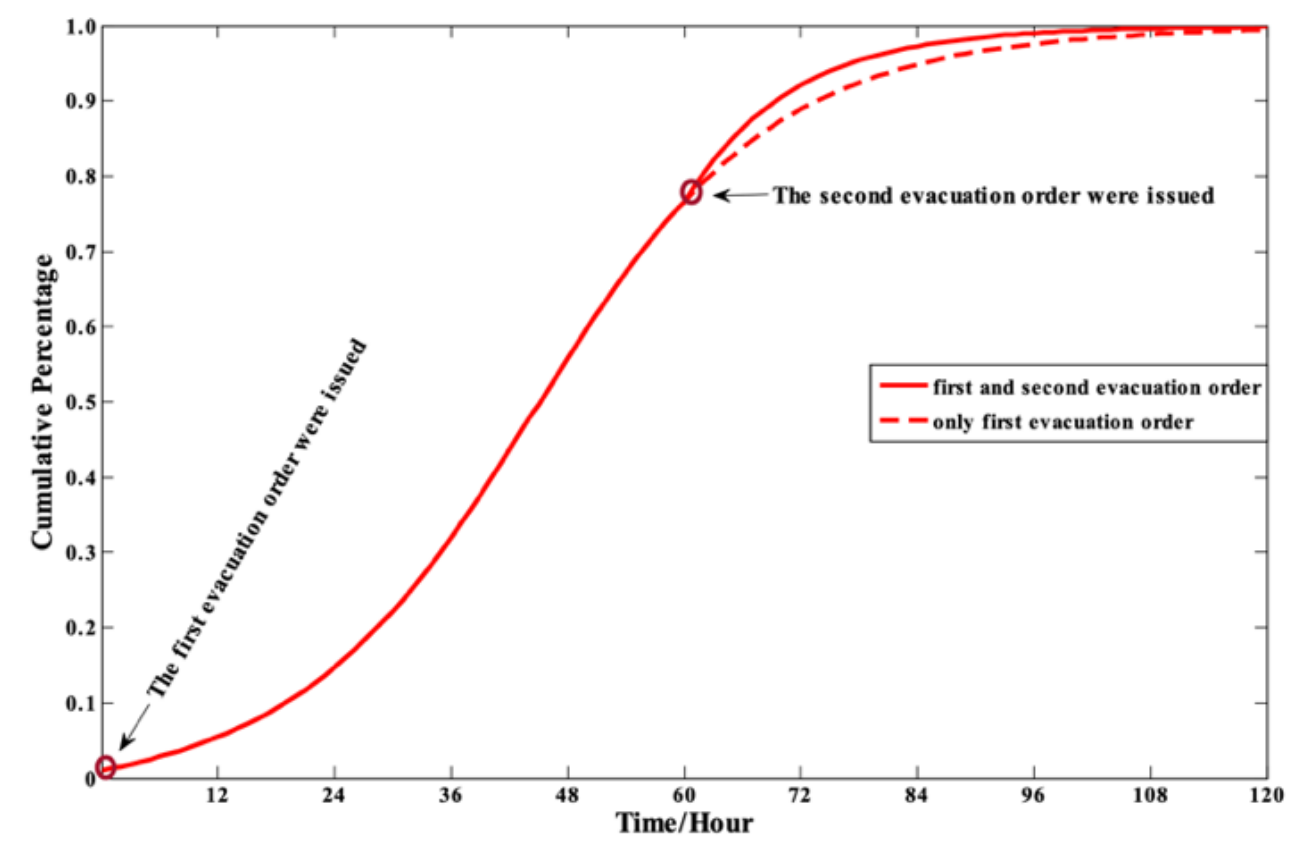

Figure 3. Total evacuation demand curve with different warning degrees (Song \& Yan, 2016).

Three ways were identified and investigated. The combination is performed by applying the following criteria:

- the highest decision-making probability among the probabilities of all the triggers ("maximum option"). This option means that households decisions are only influenced by the trigger that induces the highest evacuation demand; 
- the probability obtained by summing up the probabilities of all the triggers ("addition option") assuming that the events are mutually exclusive and the intersections of every pair of events are empty. That is, the households will decide to evacuate because of both events. It should be noted that maximum value of the resulting probability must not exceed 1;

- the "product option", where the probabilities associated with all the triggers are iteratively applied to the households that did not yet decide to evacuate when accounting for the influence of the triggers taken one at a time.

\subsection{Calculation process}

To describe and scrutinise the households' evacuation decision-making processes conveniently in theory, the related variables are identified and defined in Table 2. The variable values used are fictitious and real-world data. The real-world data are derived from the most recent data provided by the existing socio-demographic records (mainly INSEE), the critical network operators (providing the potential water levels at which their services could be disturbed and the areas of the territory that could be sensitive to these disturbances), the literature (including studies on the technical network vulnerabilities) and the results of the surveys conducted within the ambit of the RGC4 project. The real data are mainly the number of storeys and dwellings per building and the number of residents within the study target site (approximatively 10,000 persons). The fictitious data are the response curves as, unfortunately as far as we knew, no studies exist on the construction on such curves for the study area. To remedy this deficiency, a survey has been conducted within the Seine river catchment area after the 2016 and 2018 flooding events to attempt the deduction of a response curve for power outages. However, the obtained curve is not incorporated into the model, as the curve has not yet been validated.

A 1910-like flooding of the Seine does not necessarily generate stress for households living within the study area. Consequently, the model does not account for decision-making under stress. In other words, there will not be a short notice for an evacuation and households may not be evacuated from a location other than their dwelling; thus, the households are presumed to be at home at the beginning of the simulation. By doing so, the model does not account for the period of the day (diurnal, nocturnal or rush hours) conditions during the simulation. Each household is assumed to make a decision regarding what events trigger them to evacuate, should these events occur. The household evacuation decision is assumed to be an irreversible process, and once a household decides to evacuate, it would remain evacuated until the end of the simulation. It should be noted that the model is not intended for tracking the movement of households across space and time in the study area.

Figure 4 shows the flowchart of the households' evacuation decision-making model. The specific steps of the model running process are as follows: 
- Step 1: Instantiate the simulation frame. At the initialisation of a simulation, the number of people present in the towers results from the non-occupancy rate and the households' sizes.

- Step 2: Define the ranges of the uncertain values or validate the by-default ranges so that a value could be randomly assigned to each variable of the model.

- Step 3: Select the combination approach

- Step 4: Run a single simulation. The outcomes are the number of households who do not decide to evacuate (occupied apartments) and, subsequently, the number of remaining people in each of the 14 studied buildings and at each calculation step. The results are presented in the form of (1) interactive tables, (2) interactive 2D maps showing the relative spatial distribution of people to potentially care for in the target area (by assigning dark red to the maximum value and scaling to the other values in accordance as in Figure 5b) and (3) dynamic graphs showing concurrently the chronological evolution of the number of remaining persons and the 1910-like flooding hydrograph (Figure 5a). One could extract the specific results of a chosen calculation step.

- Step 5: Define the number of simulations and run them (this step is needed only if one wants to run Monte Carlo simulations). The outcomes are the descriptive statistics and the statistical distribution of the number of households who do not decide to evacuate or the number of remaining residents (this could also be done for each building and at each calculation step).

The current version of the model does not have a module intended to display the animation of the simulation dynamics. The model is not able to vividly show the interactions among households (a specific building could not been displayed to observe what is happening at each storey level; a specific household could not be tracked and its evacuation decision could not be visualised as a disappearance, for instance). However, the model is not characterised by an aspatial environment given that the buildings are set in a realistic geo-spatial landscape leading to their representation on the map as a results visualisation option.

The interest of modelling all 14 of the buildings instead of focusing on the one building that is most typical relies on two main reasons. First, the need of the Prefecture de Paris is to know how many people the public authorities would need to care for within the target area. Second, the buildings are not similar. Indeed, each of them has its specific organisation and given this organisation and the triggers which affect each of them, the need for evacuation will differ from one to another. However, when using the model, one could choose to focus on the analysis of only one or some of the buildings located in the study area. 


\begin{tabular}{ll}
\hline Variable & Definition \\
\hline & $\begin{array}{l}\text { This rate allows the generation of the number of occupied apartments in each } \\
\text { building at the instantiation of the model because it is assumed that at the moment } \\
\text { when the disaster begins, not all the apartments are occupied and all occupied } \\
\text { dwellings have their occupants present. } \\
\text { Non-occupancy } \\
\text { Bate } \\
\text { occupancy rate in the } 15 \text { th district of Paris in } 2017 \text { was } 8.6 \% \text { with around } 2 \% \text { for } \\
\text { long-lasting non-occupancy). }\end{array}$ \\
\hline Timeslot & $\begin{array}{l}\text { Time interval between two calculation steps. It allows the estimating of the number } \\
\text { of calculation steps or iterations of a simulation with regard to the duration of the } \\
\text { flooding event (which equals to approximately two months in the model). }\end{array}$ \\
& By default, it is set to 6 hours but could be user defined. \\
\hline Household size & $\begin{array}{l}\text { Number of persons belonging to each household. } \\
\text { Its values are randomly generated and range from } 1 \text { to } 4 \text { (co-ownership buildings) } \\
\text { and } 3 \text { to } 6 \text { (social housing towers) persons. Non-editable values (real-world value; } \\
\text { the average size of household is 1.81 people in the 15th district but the high-rise } \\
\text { buildings have highly densified population of approximately 10,000 inhabitants } \\
\text { and the use of these values allows estimating an initial population within the area } \\
\text { numerically close to the reality). }\end{array}$
\end{tabular}

Fraction of nonoccupied apartments at the storey level

Fraction of nonoccupied apartments at the whole building level

Decision-making probability increasing factor (storey level)

Ratio of non-occupied apartments located on the same floor in close proximity, from which starts the effect of horizontal social influence among households.

By default, it is set to 0.75 but could be user defined (assumed or fictitious value).

Ratio of non-occupied apartments of a tower, from which starts the effect of the vertical social influence among households.

By default, it is set to 0.75 but could be user defined (assumed or fictitious value).

Improvement factor by which the evacuation decision probabilities are increased when the fraction of non-occupied apartments at the storey level is attained.

By default, the average value is set to 0.25 and the standard deviation equals to 0.05 . These values could be user defined (assumed or fictitious value).

Decision-making probability increasing factor (whole building level)

Improvement factor by which the evacuation decision probabilities are increased when the fraction of non-occupied apartments at the whole building level is attained.

By default, the average value is set to 0.15 and the standard deviation equals to 0.05 . These values could be user defined (assumed or fictitious value).

Occurrence: the nominal value of the time OR the water level that induces the occurrence of each trigger.

Triggers characteristics

Evacuation decision probabilities for each type of household associated with each trigger; it consists of three lists of the evacuation rates corresponding to all the calculation steps following the occurrence of each trigger deducted from the response curves.

Targeted buildings: list of the towers affected by the effects of each trigger.

Combination approach
Represents the way to combine the evacuation decision probabilities when several triggers occur simultaneously. By default, it is set to the "maximum option" but could be user defined. 


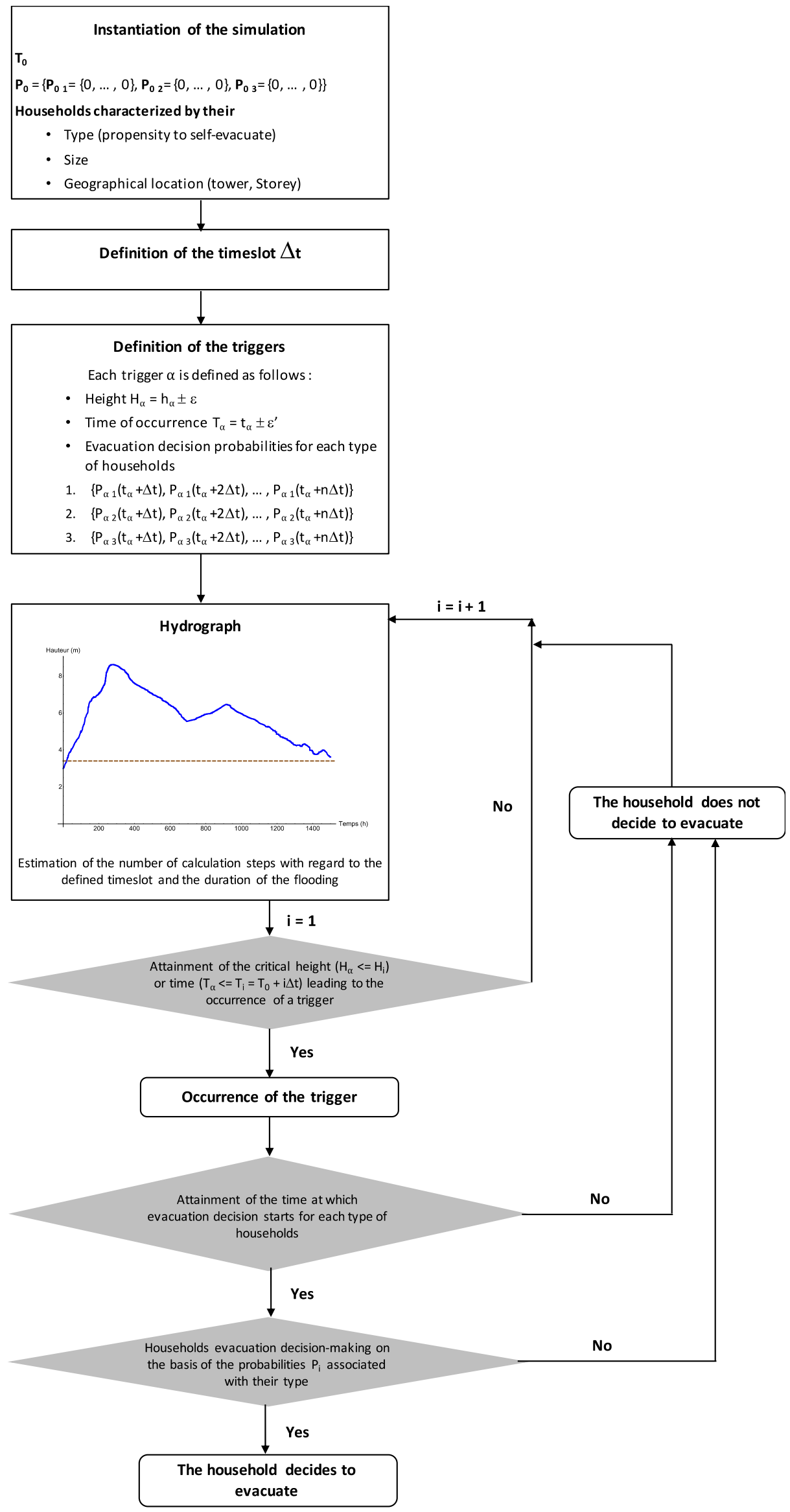

Figure 4. Flowchart of the households' evacuation decision-making modelling 


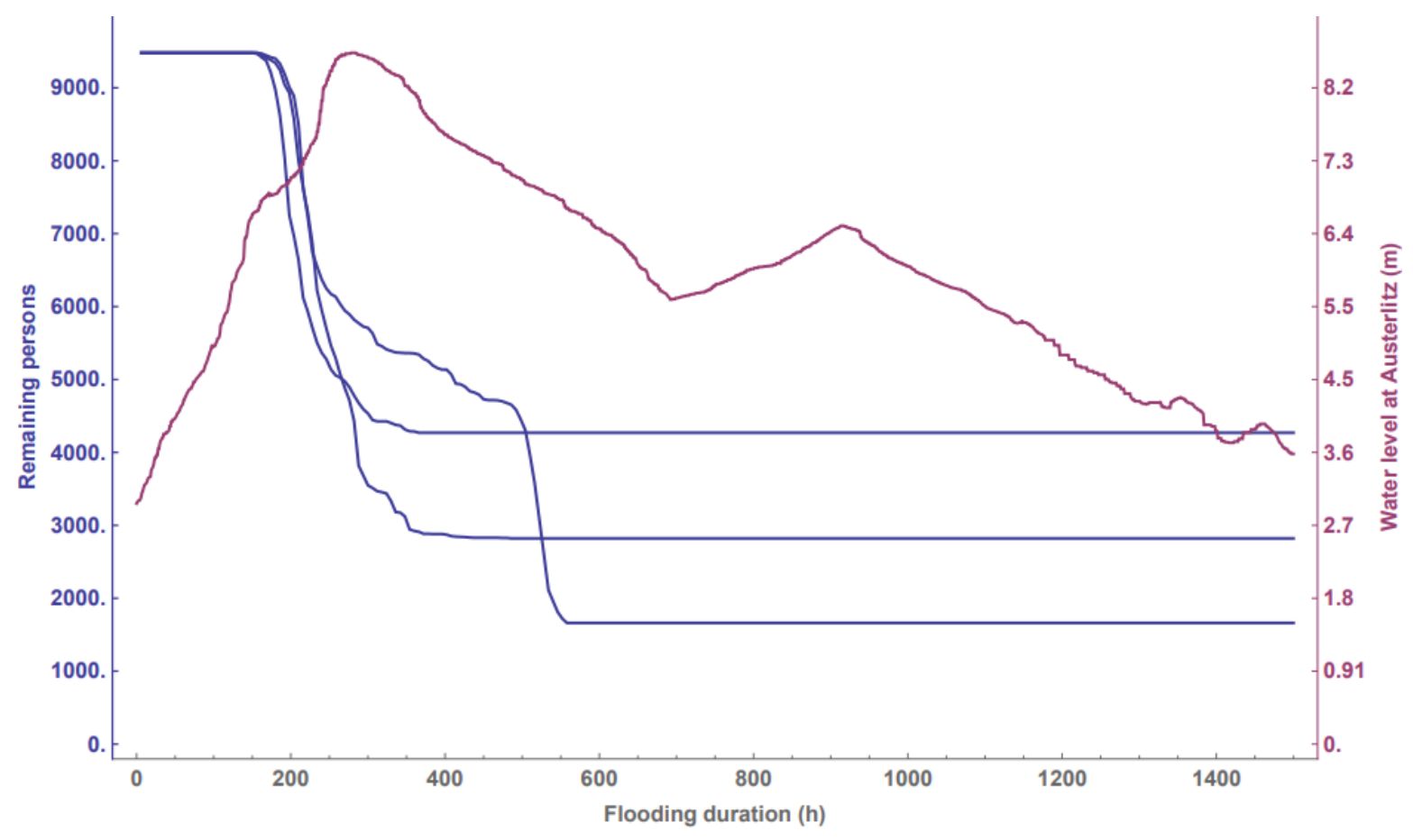

(a)

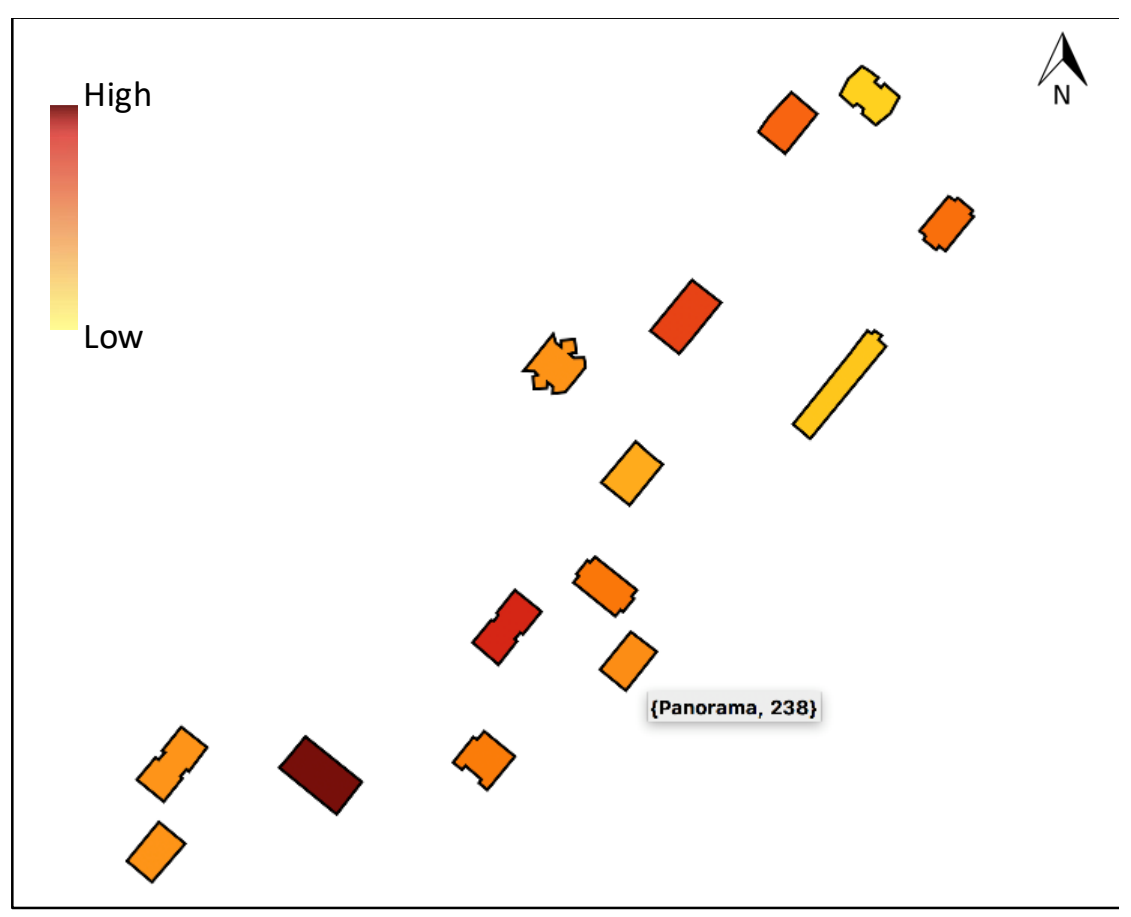

(b)

Figure 5. Samples of simulation result visualisations: (a) Graph of the temporal evolution of a scenario; (b) map indicating the number of people inside the "Panorama" tower and the relative importance of the remaining persons per building in the study area 


\section{AN ILLUSTRATIVE CASE STUDY}

Here, we present a first study to check whether the model correctly simulates the problem under study. This study also enables an examination of the potential impact of social influence and the ways to combine several triggers. For this case study, the three following scenarios are set. The information in the brackets corresponds to the height of the water at Austerlitz station or the time of occurrence, the maximum fraction of residents which could decide to evacuate under its effects and the impacted buildings.

- Scenario 1 consists of the occurrence of the following three potential evacuation triggers: (1) the closure of the traffic lanes along the Seine river due to flooding (6.4 m, 25\%, all the buildings), (2) the issuance of a recommended evacuation order $(6.6 \mathrm{~m}, 35 \%$, all the buildings) and (3) the disruption of the urban heating (7 m, 70\%, only the 3 social housing towers). This scenario can be considered as a control scenario because its three events are also part of the other two scenarios.

- Scenario 2 consists of the occurrence of the following four potential evacuation triggers: (1) the closure of the traffic lanes along the Seine river due to flooding (6.4 m, 25\%, all the buildings), (2) the issuance of a recommended evacuation order $(6.6 \mathrm{~m}, 35 \%$, all the buildings), (3) recommended evacuation of underground car parks $(6.8 \mathrm{~m}, 70 \%$, the 11 co-ownership towers) and (4) the disruption of the urban heating ( $7 \mathrm{~m}, 70 \%$, only the 3 social housing towers).

- Scenario 3 consists of the occurrence of the following four potential evacuation triggers: (1) the closure of the traffic lanes along the Seine river due to flooding $(6.4 \mathrm{~m}, 25 \%$, all the buildings), (2) the issuance of a recommended evacuation order $(6.6 \mathrm{~m}, 35 \%$, all the buildings), (3) the disruption of the urban heating ( $7 \mathrm{~m}, 70 \%$, only the 3 social housing towers) and (4) a power outage (480 hours, 90\%, all the buildings).

All the simulations started with an initial population of 3,109 households (with a total of 9,480 persons, 3,576 of whom are in the social housing towers) at random apartments. These data are used for all the simulations run in this case study. With the by default timeslot of 6 hours, each simulation consists of 250 calculation steps. The results obtained from single simulations of the scenarios with the three combination approaches are presented in Table 3. It could be concluded that the theoretical structure of the model seems to be of a certain level of realism; the results show that the number of remaining people diminishes since the number of triggers increases.

The knowledge of the evacuation demand, as well as its spatial and temporal variability is a critical piece of information for adequate management planning. The temporal distributions of the number of remaining persons obtained from the three scenarios are illustrated in Figure 6. It can be observed in this figure that, due to modelling uncertainties, there are differences between the evacuation demands in the earlier hours after the beginning of the simulations, although at that moment, the three scenarios are "supposed" to be identical (as the differentiating triggers of scenarios 2 and 3 do not occur). 
Table 3. Evacuation results of the scenarios under consideration

\begin{tabular}{lccc}
\cline { 2 - 4 } & \multicolumn{3}{c}{ Combination approach } \\
\hline & Maximum & Addition & Product \\
\hline Scenario 1 & 4,364 pers. $\left(1,715\right.$ hs. $\left.{ }^{*}\right)$ & 4,364 pers. $(1,704$ hs. $)$ & 4,319 pers. $(1,699$ hs. $)$ \\
\hline Scenario 2 & 2,731 pers. $(1,060$ hs.) & 2,256 pers. (855 hs.) & 2,323 pers. (882 hs.) \\
\hline Scenario 3 & 1,555 pers. (612 hs.) & 1,510 pers. (578 hs.) & 1,446 pers. $(573$ hs.) \\
\hline
\end{tabular}

* pers. means persons and hs. means households

The maps below (Figure $7 \mathrm{a}$ and $7 \mathrm{~b}$ ) reveal that the relative importance of the evacuation demand within the study area could change quickly. On the basis of these maps resulting from the unique simulation of scenario 3, while there are only few towers with a high level of relative evacuation demand 276 hours after the beginning of the simulation, the situation has changed 48 hours later so that there are more towers that will need great focus in the case where the public authorities will decide to evacuate people at that moment ( 324 hours after the beginning) instead of two days earlier. This just means that there is the same number of remaining persons inside these towers. Indeed, at 276 and 324 hours, the numbers of remaining persons in the high-rise buildings range from 290 to 727 and 183 to 568, respectively, while the tower with the most residents (12.33\% of the total evacuation demand) previously housed only 455 persons $(8.4 \%)$. To avoid the variability due to uncertainties and to implement evacuation activities on the basis of reliable results, one could also draw the maps relying on the results from Monte Carlo simulations.

To further analyse the potential effects of social influence and the combination approach, a sensitivity analysis was conducted to obtain a general understanding about how the households' evacuation decisions change with different conditions. For this purpose, a stochastic simulation was performed to obtain the average outputs for the parameters of interest. A total of 300 simulation trials with random initial spatial distributions of households was run for each scrutinised issue. The relatively high values of the obtained standard deviations (Tables 4 and 5) reveal that the simulation results may vary greatly from one to another because of uncertainties, which justifies the need for systematic Monte Carlo simulations running when using this model. Table 4 summarises the results of scenario 1 run with the application of the three combination approaches.

The histogram of the obtained results for the additive combination option is shown in Figure 8. It could be observed that these results (and the other ones from the Monte Carlo Simulations) are nearly normally distributed (a higher number of simulation trials could allow the shape of the distribution to be refined). A statistical analysis was thus conducted to construct normal probability density functions from the data obtained through Monte Carlo simulations (Figures 9 and 10). The observed variations among these results are too small to be significant (Figure 9); it could not be concluded that there is a difference between the three combination options. 
This situation may be due to the small number of the evacuation triggers probably leading to very little overlapping of their effect durations.

Table 5 summarises the results of scenario 1 run with and without social influence using the "maximum option" for the combination of triggers. The comparison of the results of the simulations performed ignoring the interactions among the households with those of simulations accounting for them shows that the number of remaining people when the households do not interact is higher than in the two other cases (Figure 10). This finding confirms the hypothesis that social influence will increase the likelihood that households will decide to self-evacuate their apartments when they encounter a major flooding of the Seine. Varying the settings for the fraction of non-occupied apartments provides more insights in the importance of the social influence degree, i.e., the higher the social relationships with their neighbours (meant by a lower fraction of non-occupied apartments at the storey or at the whole building level), the more likely the households are to decide to evacuate.

Furthermore, when focusing on scenario 1 and adopting the "maximum option" as the combination approach, the number of remaining people could not be lower than approximately 3,400 persons with regard to the maximum fraction of residents that could decide to evacuate under the effects of each triggering event and without accounting for social influence. Indeed, the results in Table 3 show that 4,364 people who will not evacuate when running a simulation of the scenario 1 and adopting the "maximum option" as the combination approach. Besides, the obtained result in Table 5 (mean= 4,402 persons and standard deviation 68) also demonstrates that the algorithm of this predictive evacuation model shows good performance. Even the results from the simulations accounting for social influence are higher than 3,400 persons. The reliability of the output is thus verified. From a technical point of view, this is a valuable step toward the validation of the model since a different result would mean that the algorithm is wrong.

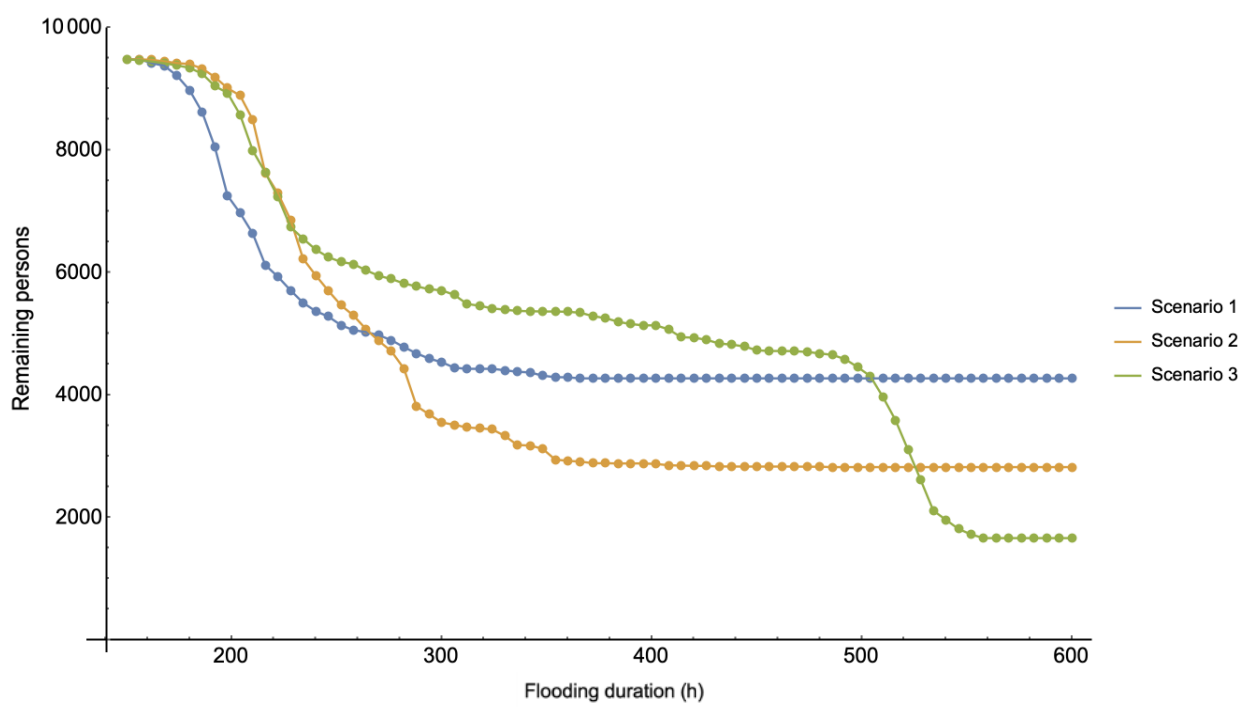

Figure 6. Comparison of the temporal evolution of persons remaining in the towers ("maximum option" results) 


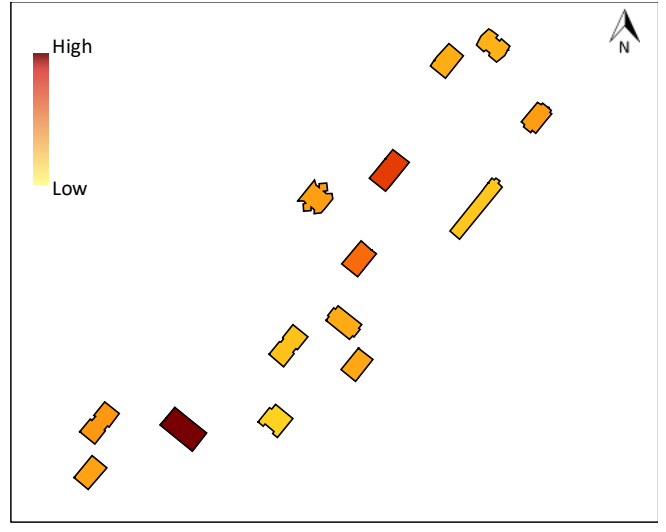

(a)

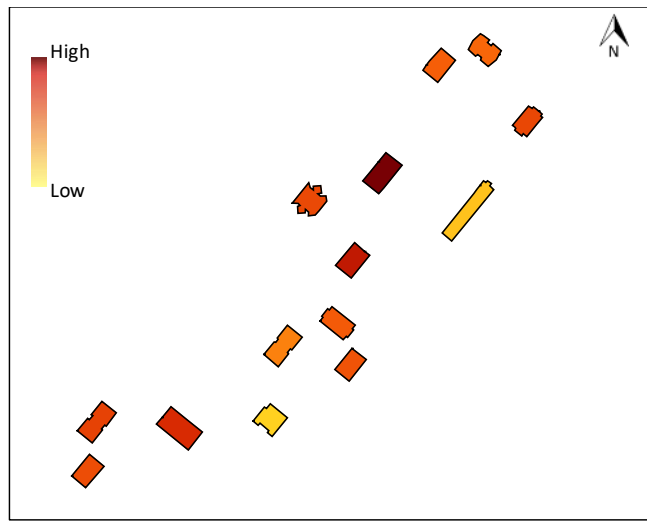

(b)

Figure 7. Spatio-temporal distributions of evacuation demands of scenario 3 (a) 276 hours and (b) 324 hours after the beginning of the flooding (unique simulation results)

Table 4. Sensitivity analysis of the effects of the combination approach on the number of remaining persons

\begin{tabular}{cccc}
\cline { 2 - 4 } & Maximum & Addition & Production \\
\hline Mean & 4,376 & 4,360 & 4,367 \\
\hline Standard deviation & 60 & 63 & 62 \\
\hline
\end{tabular}

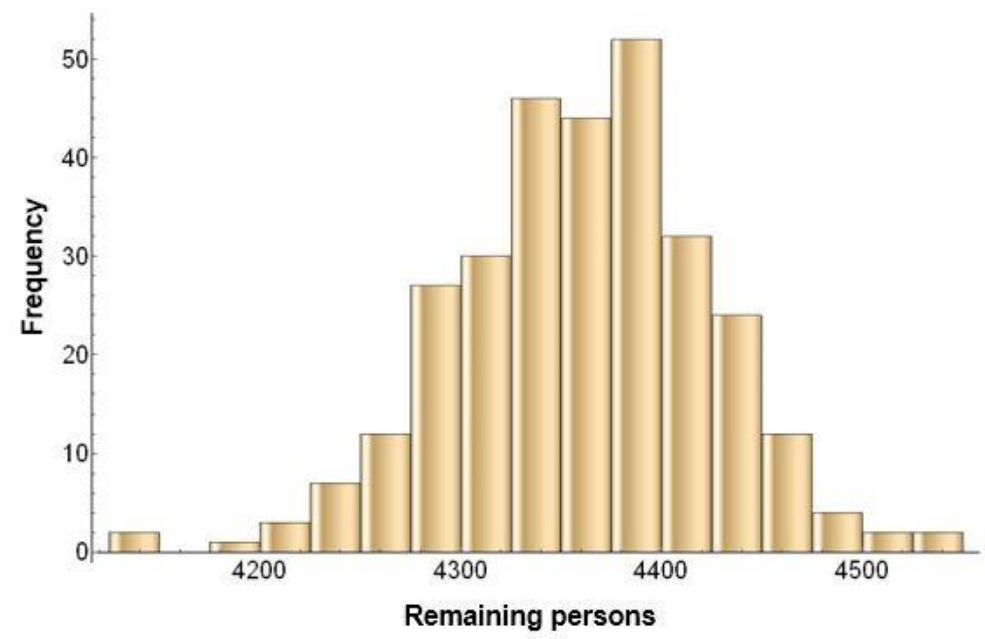

Figure 8. Histogram for the additive combination approach (300 simulation trials) 


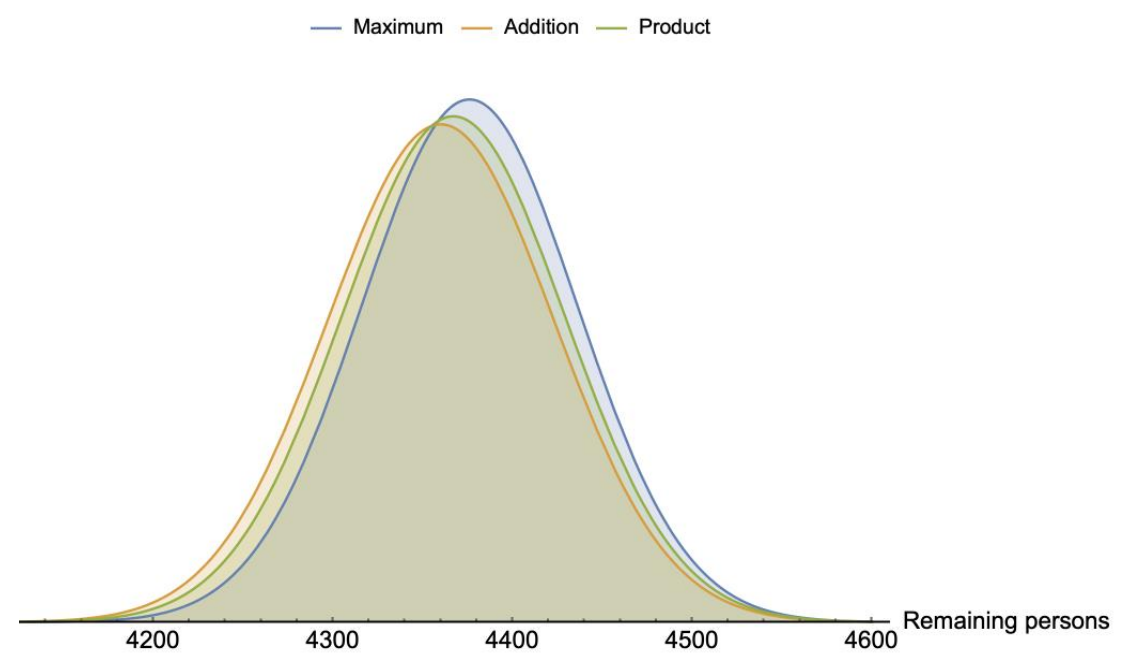

Figure 9. Statistical distributions of the remaining persons calculated with regard to the combination approach

Table 5. Sensitivity analysis of the effects of social influence on the number of remaining persons

\begin{tabular}{cccc} 
& No social influence & $\begin{array}{c}\text { Social influence when } \\
\text { non occupied } \\
\text { apartments }>\text { 50 \% }\end{array}$ & $\begin{array}{c}\text { Social influence when } \\
\text { non occupied } \\
\text { apartments }>\text { 75 \% }\end{array}$ \\
\hline Mean & 4,402 & 4,320 & 4,376 \\
\hline Standard deviation & 68 & 73 & 60 \\
\hline
\end{tabular}

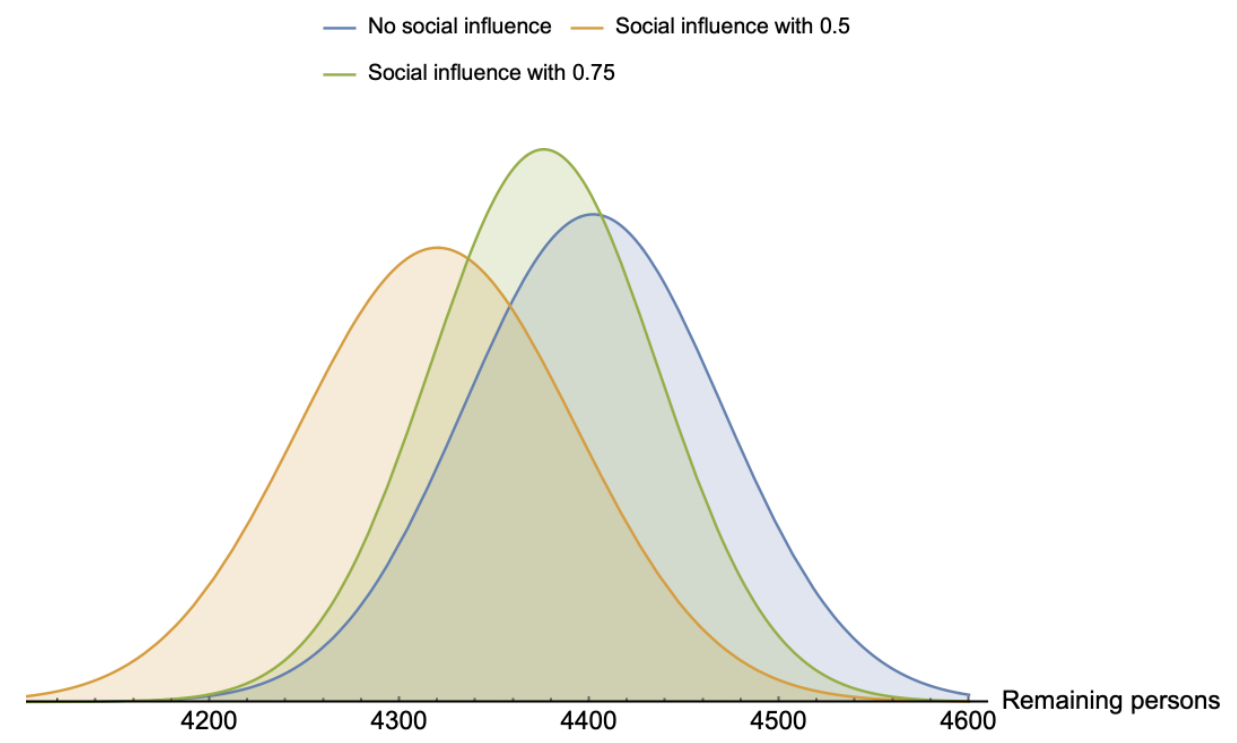

Figure 10. Statistical distributions of the remaining persons calculated with regard to social influence 


\section{CONCLUSIONS}

The probabilistic agent-based model presented in this paper is intended to support the estimation of the evacuation demand in the towers of the 15th district in Paris. By achieving the objective of accounting for social influence, multiple triggering events and uncertainties, this model could lead to a better realism in the results when predicting the number of people to care for if evacuation of the Parisian 15th district is needed. Indeed, by accounting for evacuation decision-making factors that are not or are less commonly considered by the existing evacuation models, this study contributes to the improvement of the comprehensiveness of the evacuation determinants by the evacuation modelling engineering. Additionally, as the comprehensiveness of the decision-making factors integrated in the evacuation model increases, so does the reliability of its outputs.

Though the evacuation decision is difficult to predict due to the difficulty of determining the complex evacuees' behaviours, the illustrative case study has led to insights about this first step towards a tool for simulating households' decisions to evacuate. Globally, the model seems to correctly simulate the households' evacuation decision-making processes through the decrease in the number of people in the buildings over time as soon as triggers occur. The testing simulations demonstrate that the current version of the model can be run without identified bugs and can already be used for running a series of scenarios that could result from a major flood of the Seine river. The current version of the model can also be used for any other study area. In that case, instead of relying on the interaction rules between households located on the same storey or living in the same building, one will consider a given area around the households' dwellings.

However, one must define the proper response curves for each evacuation trigger to generate more realistic results. For this purpose and within the ambit of this study, a survey was conducted after the 2016 and 2018 floods to construct a response curve associated with power outages in the Paris urban area. This response curve is currently being integrated into the model, which is still under development. An important step remains to be performed after defining response curves. This step will consist of validating the model. Indeed, the realism of the results generated by the model can be questioned because the model has not yet been validated. As stated by Pel (2011), the validation of evacuation model outcomes is, in most cases, difficult or even impossible because real data for evacuations are limited or unavailable. However, if the data needed for the calibration and the validation are available, the model can be adjusted to simulate the households' decisions to evacuate or not with a higher level of realism. Moreover, we acknowledge another limitation of the model, which is the time-consuming computations. First, the running times vary according to the defined timeslot because the higher the number of calculation steps, the greater the number of iterative calculations needed for a simulation. Second, the model considers only triggers liable to induce households to evacuate at the expense of those that can encourage them to stay at their apartments, such as the risk management activities to reduce the risk level (the long lasting duration of the flooding makes it possible to intervene for reducing the risk or its damage). 
Despite its obvious drawbacks at this stage, the model offers a constructive basis for researchers and policymakers to better investigate the evacuation demands while taking into account different households characteristics and the combination of the effects of various evacuation triggers under social influence conditions. The model is a unique and valuable tool to predict the number of households who will not decide to evacuate to help risk managers estimate the evacuation needs, such as the identification of where to take the remaining residents, the planning of safe traffic lanes and the definition of the appropriate instructions to guide people to safer places. The model also permits the raising of the important question regarding the need to construct response curves for evacuation triggers different from the evacuation orders/instructions and hazard-related features, which to the best of our knowledge, has not yet been raised in the existing literature on evacuation modelling. Future studies could further investigate this question.

\section{REFERENCES}

Ahsan, N. S., Takeuchi, K., Vink, K. \& Ohara, M. (2016). A Systematic Review of the Factors Affecting the Cyclone Evacuation Decision Process in Bangladesh. Journal of Disaster Research, Volume 11, Issue 4, pp. 742-753. DOI 10.20965/jdr.2016.p0742

Albino, V., Carbonara, N. \& Giannoccaro, I. (2007). Supply Chain Cooperation in Industrial Districts: A Simulation Analysis. European Journal of Operational Research, Volume 177, Issue 1, pp. 261-280. DOI 10.1016/j.ejor.2005.12.007

Bangate, J., Dugdale, J., Beck, E. \& Adam, C. (2017). SOLACE a Multi-agent Model of Human Behaviour Driven by Social Attachment During Seismic Crisis. In: Proceedings of the 4th International Conference on Information and Communication Technologies for Disaster Management (ICT-DM'17), Münster, Germany, December 11-13, 2017, 9 p.

Chang, S. E., Pasion, C., Yavari, S. \& Elwood, K. (2009). Social Impacts of Lifeline Losses: Modeling Displaced Population and Health Care Functionality. In: Tang, A. \& Werner, S. (Eds.), Proceedings of 2009 Technical Council on Lifeline Earthquake Engineering (TCLEE) Conference, Oakland, USA, June 22 - July 1, pp 563-572.

Chatterjee, C. \& Mozumder, P. (2015). Hurricane Wilma, Utility Disruption, and Household Wellbeing. International Journal of Disaster Risk Reduction, Volume 14, Part 4, pp. 395402. DOI 10.1016/j.ijdrr.2015.09.005

Chen, X. \& Zhan, F. B. (2008). Agent-based Modelling and Simulation of Urban Evacuation: Relative Effectiveness of Simultaneous and Staged Evacuation Strategies. Journal of the Operational Research Society, Volume 59, Issue 1, pp. 25-33. DOI 10.1057/palgrave.jors. 2602321 
Christensen, K. \& Sasaki, Y. (2008). Agent-Based Emergency Evacuation Simulation with Individuals with Disabilities in the Population. Journal of Artificial Societies and Social Simulation, Volume 11, Issue 3, 9 p.

Cova, T. J. \& Johnson, J. P. (2002). Microsimulation of Neighborhood Evacuations in the Urban - Wildland Interface. Environment and Planning A: Economy and Space, Volume 34, Issue 12, pp. 2211-2229. DOI 10.1068/a34251

Dash, N. \& Gladwin, H. (2007). Evacuation Decision Making and Behavioral Responses: Individual and Household. Natural Hazards Review, Volume 8, Issue 3, pp. 69-77. DOI 10.1061/(ASCE)1527-6988(2007)8:3(69)

Fang, Z., Li, Q., Li, Q., Han, L. D. \& Wang, D. (2011). A Proposed Pedestrian Waiting-time Model for Improving Space-time Use Efficiency in Stadium Evacuation Scenarios. Building and Environment, Volume 46, Issue 9, pp. 1774-1784. DOI 10.1016/j.buildenv.2011.02.005

Fraser, S. A., Leonard, G. S. \& Johnston, D. M. (2013). Intended Evacuation Behaviour in a Local Earthquake and Tsunami at Napier. Scientific report, 55 p.

Fraser, S. A., Wood, N. J., Johnston, D. M., Leonard, G. S., Greening, P. D. \& Rossetto, T. (2014). Variable Population Exposure and Distributed Travel Speeds in Least-cost Tsunami Evacuation Modelling. Natural Hazards and Earth System Sciences, Volume 14, pp. 29752991. DOI 10.5194/nhess-14-2975-2014

Fu, H. \& Wilmot, C. G. (2004). Sequential Logit Dynamic Travel Demand Model for Hurricane Evacuation. Transportation Research Record: Journal of the Transportation Research Board, Volume 1882, Issue 1, pp. 19-26. DOI 10.3141/1882-03

Fujiki, K. \& Laleau, M. (2019). A Geographic Approach for Spatializing Emergency Sheltering Needs in a Crisis Situation - Case Study of a Massive Evacuation Triggered by a Major Seine Flood in Ile de France Region. La Houille Blanche, Number 3-4, pp. 75-83. DOI $10.1051 / \mathrm{hb} / 2019043$

Fujiki, K. (2017). Etude prospective des impacts sociaux d'une inondation majeure en région Ile-de-France. Disparités socio-spatiales dans la prise en charge des populations franciliennes en situation de crise et post-crise : Une analyse cartographiée et quantifiée des besoins des ménages, de l'évacuation à la reconstruction. (Prospective study of the social impacts of a major flood in the Ile-de-France region. Socio-spatial disparities in the care of Ile-de-France populations in crisis and post-crisis situations: A mapped and quantified analysis of household needs, from evacuation to reconstruction.) Phd Thesis (In French), Université Jean Moulin Lyon 3, France, 485 p. Available online at https://tel.archivesouvertes.fr/tel-01760843/document

Han, L. D., Yuan, F. \& Urbanik II, T. (2007). What Is an Effective Evacuation Operation? Journal of Urban Planning and Development, Volume 133, Issue 1, pp. 3-8. DOI 10.1061/(ASCE)0733-9488(2007)133:1(3) 
Hawe, G. I., Coates, G., Wilson, D. T. \& Crouch, R. S. (2012). Agent-based Simulation for Large-scale Emergency Response: A Survey of Usage and Implementation. ACM Computing Survey, Article n 8, Volume 45, Issue 1, 58 p. DOI 10.1145/2379776.2379784

Hofflinger, A., Somos-Valenzuela, M. A. \& Vallejos-Romero, A. (2019). Response Time to Flood Events Using a Social Vulnerability Index (ReTSVI). Natural Hazards and Earth System Sciences, Volume 19, Issue 1, pp. 251-267. DOI 10.5194/nhess-19-251-2019

Institut National de la Statistique et des Études Économiques (INSEE - French National Institute for Statistics and Economic Studies) (2016). Population and Housing Census. Available online at https://www.insee.fr/fr/information/4172214

Jumadi, J., Heppenstall, A. J., Malleson, N. S., Carver, S. J., Quincey, D. J. \& Manville, V. R. (2018). Modelling Individual Evacuation Decisions during Natural Disasters: A Case Study of Volcanic Crisis in Merapi, Indonesia. Geosciences, Volume 8, Issue 6:196, 30 p. DOI $10.3390 /$ geosciences 8060196

Kailes, J. I. \& Enders, A. (2007). Moving Beyond "Special Needs" A Function-Based Framework for Emergency Management and Planning. Journal of Disability Policy Studies, Volume 17, Issue 4, pp. 230-237. DOI 10.1177/10442073070170040601

Kakimoto, R. \& Yamada, F. (2014). Factors in Stimulating Evacuation Behavior during Floods. In: Proceedings of the 10th International Conference of the International Institute for Infrastructure Resilience and Reconstruction (3IR2), Purdue, USA, May 20-24, 2014, pp 7581

Kalafatas, G. \& Peeta, S. (2009). Planning for Evacuation: Insights from an Efficient Network Design Model. Journal of Infrastructure Systems, Volume 15, Issue 1, pp. 21-30. DOI 10.1061/(ASCE)1076-0342(2009)15:1(21)

Kasereka, S., Kasoro, N., Kyamakya, K., Doungmo Goufo, E.-F., Chokki, A. \& Yengo, M. V. (2018). Agent-based Modelling and Simulation for Evacuation of People from a Building in Case of Fire. Procedia Computer Science, Volume 130, pp. 10-17. DOI 10.1016/j.procs.2018.04.006

Lamb, S., Walton, D., Mora, K. \& Thomas, J. (2012). Effect of Authoritative Information and Message Characteristics on Evacuation and Shadow Evacuation in a Simulated Flood Event. Natural Hazards Review, Volume 13, Issue 4, pp. 272-282. DOI 10.1061/(ASCE)NH.15276996.0000070

Lim, M. B. B., Lim, H. R., Piantanakulchai, M. \& Uy, F. A. (2016). A household-level Flood Evacuation Decision Model in Quezon City, Philippines. Natural Hazards, Volume 80, Issue 3, pp. 1539-1561. DOI 10.1007/s11069-015-2038-6

Lindell, M. K., Lu, J.-C. \& Prater, C. S. (2005). Household Decision Making and Evacuation in Response to Hurricane Lili. Natural Hazards Review, Volume 6, Issue 4, pp. 171-179. DOI 10.1061/(ASCE)1527-6988(2005)6:4(171) 
Lindell, M. K., Prater, C. S., Gregg, C. E., Apatu, E. J. I, Huang, S.-K. \& Wu H. C. (2015). Households' Immediate Responses to the 2009 American Samoa Earthquake and Tsunami. International Journal of Disaster Risk Reduction, Volume 12, pp. 328-340. DOI 10.1016/j.ijdrr.2015.03.003

Liu, Z., Jalalpour, M., Jacques, C., Szyniszewski, S., Mitrani-Reiser, J., Guest, J. K., Igusa, T. \& Schafer, B. W. (2012). Interfacing Building Response with Human Behavior Under Seismic Events. In: Proceedings of the 15th World Conference on Earthquake Engineering, Lisbon, Portugal, September 24-28, 10 p.

Luathep, P., Suwansunthon, A., Sutthiphan, S. \& Taneerananon, P. (2013). Flood Evacuation Behavior Analysis in Urban Areas. Journal of the Eastern Asia Society for Transportation Studies, Volume 10, pp. 178-195. DOI 10.11175/easts.10.178

Lv, Y., Huang, G. H., Guo, L., Li, Y. P., Dai, C., Wang, X. W. \& Sun, W. (2013). A Scenariobased Modeling Approach for Emergency Evacuation Management and Risk Analysis under Multiple Uncertainties. Journal of Hazardous Materials, Volume 246-247, pp. 234-244. DOI 10.1016/j.jhazmat.2012.11.009

Madireddy, M., Medeiros, D. J. \& Kumara, S. (2011). An Agent Based Model for Evacuation Traffic Management. In: Proceedings of the Proceedings of the 2011 Winter Simulation Conference (WSC), Phoenix, USA, December 11-14, pp. 222-233. DOI 10.1109/WSC.2011.6147753

Mostafizi, A., Wang, H., Cox, D., Cramer, L. A. \& Dong, S. (2017). Agent-based Tsunami Evacuation Modeling of Unplanned Network Disruptions for Evidence-driven Resource Allocation and Retrofitting Strategies. Natural Hazards, Volume 88, Issue 3, pp. 1347-1372. DOI 10.1007/s11069-017-2927-y

Murray-Tuite, P. \& Wolshon, B. (2013). Evacuation Transportation Modeling: An Overview of Research, Development, and Practice. Transportation Research Part C: Emerging Technologies, Volume 27, pp. 25-45. DOI 10.1016/j.trc.2012.11.005

Nagarajan, M., Shaw, D. \& Albores, P. (2012). Disseminating a Warning Message to Evacuate: A Simulation Study of the Behaviour of Neighbours. European Journal of Operational Research, 220, 810-819. DOI 10.1016/j.ejor.2012.02.026

Nateghi, R., Guikema, S. D. \& Quiring, S. M. (2011). Comparison and Validation of Statistical Methods for Predicting Power Outage Durations in the Event of Hurricanes. Risk Analysis, Volume 31, Issue 12, pp. 1897-1906. DOI 10.1111/j.1539-6924.2011.01618.x.

Nikolic, I. \& Kasmire, J. (2013). Theory. In: van Dam, K. H., Nikolic, I. \& Lukszo, Z. (eds), Agent-Based Modelling of Socio-Technical Systems. Dordrecht, The Netherlands, pp. 1171

Olsvik, A., Mehdizadeh, R., Deck, O., Edjossan-Sossou, A. M., Judek, C. \& Vuillet, M. (2018). Modelling Infrastructural Cascade Failure with Multi-Agent Simulation: Application to a 
Case of Flooding. In: Proceedings of the 10th Materials and structures reliability symposium (JFMS 2018), Bordeaux, France, March 27-28, 2018, 10 p.

Organisation for Economic Cooperation and Development (OECD) (2014 a). Seine Basin, Ilede-France: Resilience to major floods. Main results and recommendations. OECD Publishing, Paris, 23 p. Available online at https://www.oecd.org/gov/risk/Flood-riskmanagement-seine-river-executive-summary.pdf

Organisation for Economic Cooperation and Development (OECD) (2014 b). Seine Basin, Ilede-France, 2014: Resilience to major floods. OECD Publishing, Paris, 204 p. DOI 10.1787/9789264208728-en

Pel, A. J. (2011). Transportation Modeling for Regional Evacuation. Phd Thesis, Delft University of Technology, Netherlands, $170 \mathrm{p}$.

Rabemalanto, N., Pottier, N., Edjossan-Sossou, A. M. \& Vuillet, M. (2020). Household Resilience to Major Slow Kinetics Floods: A Prospective Survey of the Capacity to Evacuate in High Rise Buildings in Paris. Natural Hazards and Earth System Sciences, Discuss., DOI 10.5194/nhess-2020-150 (in review)

Rangel-Ramírez, J. G., Schubert, M. \& Faber, M. H. (2019). Probabilistic Evacuation Assessment with Real-time Monitoring Information. In: Proceedings of the 13th International Conference on Applications of Statistics and Probability in Civil Engineering (ICASP13), Seoul, South Korea, May 26-30, 2019, 8 p.

Reed, D. A., Powell, M. D. \& Westerman, J. M. (2010). Energy Infrastructure Damage Analysis for Hurricane Rita. Natural Hazards Review, Volume 11, Issue 3, pp 102-109. DOI 10.1061/(ASCE)NH.1527-6996.0000012

Riad, J. K., Norris, F. H. \& Ruback, R. B. (1999). Predicting Evacuation in Two Major Disasters: Risk Perception, Social Influence and Access to Resources. Journal of Applied Social Psychology, Volume 29, Issue 5, pp 918-934. DOI 10.1111/j.15591816.1999.tb00132.x

Ronchi, E., Kuligowski, E. D., Reneke, P. A., Peacock, R. D. \& Nilsson, D. (2013). The Process of Verification and Validation of Building Fire Evacuation Models. National Institute of Standards and Technology (NIST) Technical Note 1822, 79 p. DOI 10.6028/NIST.TN.1822

Schultz, C. H., Koenig, K. L. \& Lewis, R. J. (2003). Implications of Hospital Evacuation after the Northridge, California, Earthquake. The New England Journal of Medicine, Volume 348, pp. 1349-1355. DOI 10.1056/NEJMsa021807

Solis, D., Thomas, M. H. \& Letson, D. (2010). An Empirical Evaluation of the Determinants of Household Hurricane Evacuation Choice. Journal of Development and Agricultural Economics, Volume 2, Issue 3, pp. 188-196. 
Song, Y. \& Yan, X. (2016). A Method for Formulizing Disaster Evacuation Demand Curves based on SI Model. International Journal Environmental Research and Public Health, Volume 13, Issue 10, 21 p. DOI 10.3390/ijerph13100986

Tavares, R. M. \& Ronchi, E. (2015). Uncertainties in Evacuation Modelling: Current Flaws and Future Improvements. In: Proceedings of the 6th Human Behaviour in Fire Symposium, Cambridge, UK, September 28-30, 2015, 13 p.

Tobin, G. A., Whiteford, L. M., Jones, E. C., Murphy, A. D., Garren, S. J. \& Padros, C. V. (2011). The Role of Individual Well-being in Risk Perception and Evacuation for Chronic vs. Acute Natural Hazards in Mexico. Applied Geography, Volume 31, Issue 2, pp. 700-711. DOI 10.1016/j.apgeog.2010.12.008

Ukkusuri, S. V., Hasan, S., Luong, B., Doan, K., Zhan, X., Murray-Tuite, P. \& Yin, W. (2017). A-RESCUE: An Agent Based Regional Evacuation Simulator Coupled with User Enriched Behavior. Networks and Spatial Economics, Volume 17, Issue 1, pp. 197-223. DOI 10.1007/s11067-016-9323-0

Wang, J., Wang, M., Zhou, J., Zuo, Q. \& Shi, X. (2020). Simulation Based Optimal Evacuation Plan in Vertical Ship Lift: A Case Study. Engineering Computations, Volume 37, Issue 5. DOI 10.1108/EC-05-2019-0212

Wright, K. C. \& Johnston, D. M. (2010). Post-earthquake Sheltering Needs; How Loss of Structures and Services Affects Decision Making for Evacuation. In: Proceedings of the 2010 New Zealand Society for Earthquake Engineering NZSEE Conference, Wellington, New Zealand, March 26-28, 2010, 7 p.

Zale, J. J. \& Kar, B. (2012). A GIS-based Football Stadium Evacuation Model. Southeasttern Geographer, Volume 52, Issue 1, pp. 70-89. DOI 10.1353/sgo.2012.0002 